\title{
Raw Material Counting Scale for Small Scale Industries
}

\author{
1st Anil N. Pachare \\ Electronics Engineering Department \\ Vishwakarma Institute Of Technology \\ Pune, India \\ 3nd Siddhi Jadhav \\ Industrial Engineering Department \\ Vishwakarma Institute Of Technology \\ Pune, India
}

\author{
2nd Dhanshree S. Panchwatkar \\ Electronics Engineering Department \\ Vishwakarma Institute Of Technology \\ Pune, India \\ 4th Snehal Gavade \\ Industrial Engineering Department \\ Vishwakarma Institute Of Technology \\ Pune, India
}

\begin{abstract}
In many applications of object counting conveyor belt is required. In this process the object detected by using the IR sensors, ultra-sonic sensor or image processing. But it cannot be used in small scale industries because it is not cost efficient for SSI. So we are proposing a counting system which is low cost, automatic and time efficient. Which can count the number of objects using a counting scale. First step is to weight the load by putting it on the load cell. Then select the size of the objects manually .Then number of objects are estimated by dividing the total weight which is put on a load cell by the average weight of an individual object as per the different sizes of object .This procedure avoids counting individual parts and can save time,requies less man power, money and also improve the accuracy. In this project we observed and verified the effect of the estimation procedure used to determine the average weight, measurement error, and discretization on the accuracy of the counting scale. We had provided some guidelines for the successful implementation of scale counting and suggested a change in the standard procedure of weight using counting scale.
\end{abstract} Count.

Keywords-Load cell, switches, Display, Raw parts, Wright,

\section{INTRODUCTION}

There are many industries which faces the problem of counting of import Raw material from supplier. The high scale industries uses automation. They uses the conveyor belt for this task. But in small scale industries this system is not suitable. In the small scale industries either they can trust on supplier or worker who counts a raw material manually. But this process requires so much time and also the accuracy of this counting is very less and for this task more man power is required approximately 3-4 workers(depending on the number of objects).This system is not cost efficient so we are working on this problem statement and provide the solution to the industry. This is an automotive industry and we have to count heavy raw material. We had provided a solution which is based on counting scale. Depending on different size and weight of Raw material we had provided different switches for selection of size. It should be selected by worker. Then the system will calibrate the weight of objects and system will store the data of average weight (dividing the total weight by weight of individual object) and a count will display on the LCD.

\section{LITERATURE SURVEY}

Counting is the issue of the industries because it requires money, time and man power. Currently, lot of research is being made on automatic object counting on the objects by using different methods. We are in small scale industries and working on weight counting scale. We had taken some of sample test. We took 10 sample tests of different objects, got 10 different reading and then calculated an average of this weight. For calculating the count of objects we weight some of objects divided it by the average weight. This process will automatically done in microcontroller as program stored in it. For that the average weight of different size is already stored. Manually only we have to select the switch for size. Depending on the total weight it shows the perfect count.

[1] Load cell is used to sensing the weight of objects. It is a one type of transducer which converts the weight into the electrical signal. When the load is applied on load cell column it's compressed and change their length, the length change is not directly measured it is connected to the stain gauge work as a secondary transducer it's recorded the displacement of load column. When the strain gauge compressed its change their displacement and it has resistance which is varies. The change in resistance is the output voltage change and could be amplified using a differential amplifier.

[2] For controlling and automatically measurement using microcontroller. For this project we are using the Arduino Uno as our main controller (microcontroller Atmel 328).

[3] For display the count we are using the LCD display $16 \mathrm{X} 2$. Which is interfaced with the microcontroller using connecting wires.

[4] Switches are used to select the different sizes. This is a push switch, which is change the size depending input high/low. 


\section{PROBLEM IDENTIFICATION/OBJECTIVES}

- The problem identified is related to counting of raw material at the receiving side.

- The raw material is delivered to the company on the requirements, that it's daily or with a gap of 2 days or even weekly.

- The material is counted by the supplier's side only.

- After some days or maybe months, company observes that there is shortage of raw material which was not supposed to be short.

- Implementation of the counting system which require

$>$ Less time

$>$ Less man power.

- By establishing the technique for counting the raw material and thereby reducing the problem of shortage.

\section{DIFFERENT SOLUTIONS}

1. Counting using weight

Put random numbers of the objects on the weight machine. Depending upon the weight, system will display the no of objects. (An average weight of the one object is already stored its dividing the weight of machine)

2. Counting using Conveyor Belt

The objects are put on the conveyor belt by one side and it's counted by other side. The object is counted when it is passed from IR Sensor.

3. Counting using Moving Wheel

Put objects to a counting storage then the object will Drop into a moving wheel which consist of number of holes. The size of hole is depended on the size of object. Then it will pass through a single hole. Then it is counted by using IR sensor.

4. Counting using Beans

Put objects on a slider. Make a bean of number rows and number of columns depending on size of one object fill rows and columns by moving the bean and count no of objects by calculating height of bean and number of columns.

5. Counting using Image processing

Put the objects on the conveyor belt. As the objects start to move it will scan by a camera. In this process the object will detect by its size and the object will be counted.

6. Counting using RFID

Fix the RFID Tag on import objects and it will scan by using RFID Reader system, and using controller it will shows the count of objects.

7. Counting using Barcode scanning

Stick the barcode tag on import objects and it will scan by using barcode scanning machine it will shows the count of objects.

\section{WORKING ON WEIGHT COUNTING SYSTEM}

This method is having weight measurement module (load cell), micro-controller (Arduino Uno), HX711 load cell amplifier module and switches for selection of a size.

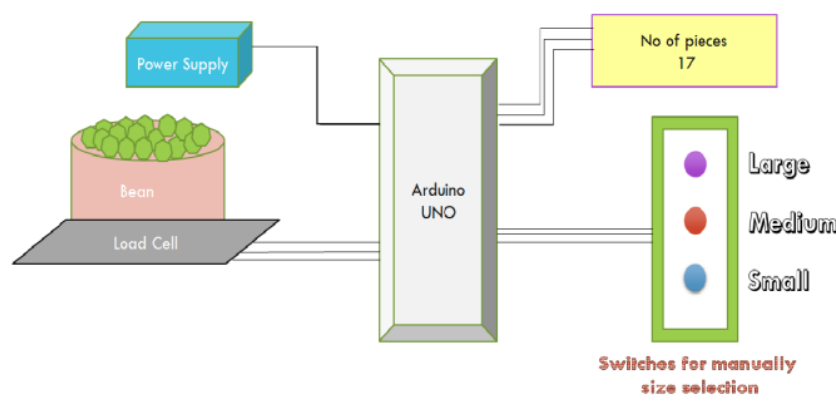

Fig. block diagram

The dc supply is provided to Arduino UNO by Power supply.The Main platform we are using to build the project is Arduino-UNO which gives us the flexibility to write the code more effectively in convenient way. It also provides us features like Inexpensive, Cross platform, Simpler and clear programming environment, Open source and extensible software easy for beginners. Ardiuno UNO normally connect it to a computer with a USB cable and power it with an AC to-DC adapter or battery to get starts. In the project we will store the three different sizes of an average weights into the Arduino Uno. Depending on the capacity of the load cell (we are using the $200 \mathrm{Kg}$ maximum capacity of a load cell) put the weight on it. Firstly select the switch of size of the material or object. Then put on the load cell and the total weight should be less $200 \mathrm{~kg}$. Arduino UNO calculated the total weight divided by the average weight and show the count on LCD display.

\section{SAMPLE TESTING}

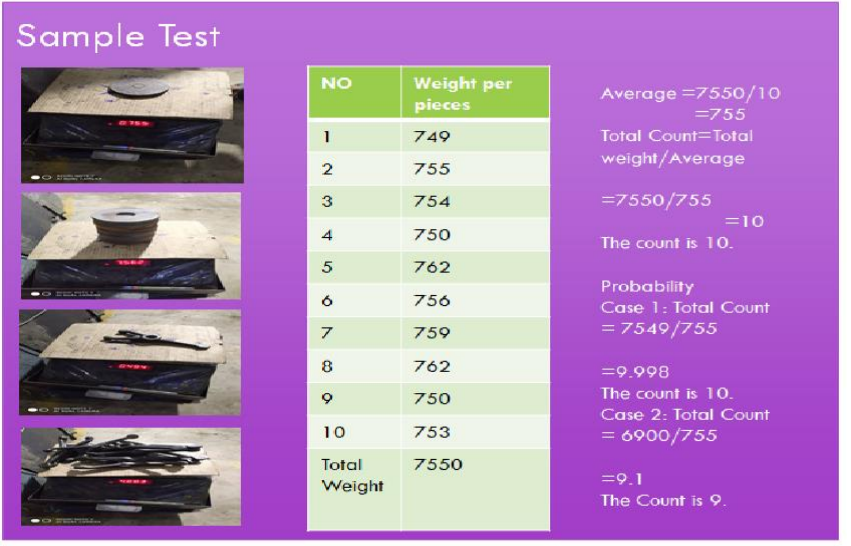

We take a 10 random object from the import material and weight of every object. Get the 10 different reading depending on the reading the weight is varies in between 749 $\mathrm{Gm}-762 \mathrm{Gm}$. Take an average weight of the object. There are some probabilities which can cause to error (Arduino uno will not able show the count). 


\section{LOAD CELL:}

\section{COMPONENT DESCRIPTION}

Load cells is the transducers which are used to measure the weight using force applied on it. The output of load cell is in the form of electrical signal proportional to input force. Strain gauges are the most common load cells in industry. The commonly used load cells are strain gauges. These load cells are particularly stiff, have very good resonance values, and tend to have long life cycles in application.

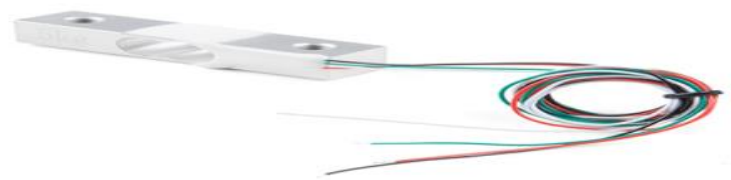

The strain gauges have property of stretching and contracting according to the appropriate deformation of the material of load cells. The values of deformation are very small and related to the stress and strain of that material load cell is having at the time. The changes in resistance are the strain gauge give out an electrical value change into is used to calculate the load placed on the load cell. Strain gauge is basically a planer resistor gives the electrical output.

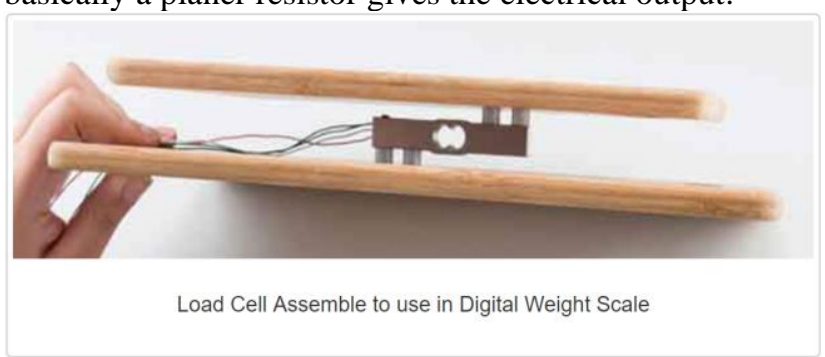

Fig: load cell

HX711 Module:

Load cell will give the output in micro volts and Arduino is not capable of reading these values directly therefore amplification is required.

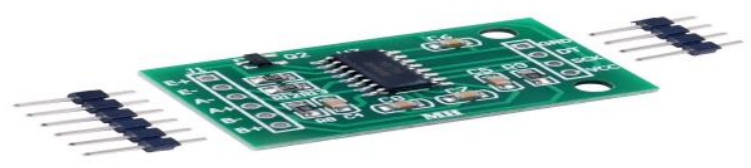

For this best solution is to use HX711 amplifier which is a 24-bit analog to digital amplifier and gives accurate output from a load cell. The HX711 amplifier consist of 10 pins, there is four pins are used to interfacing with Arduino.

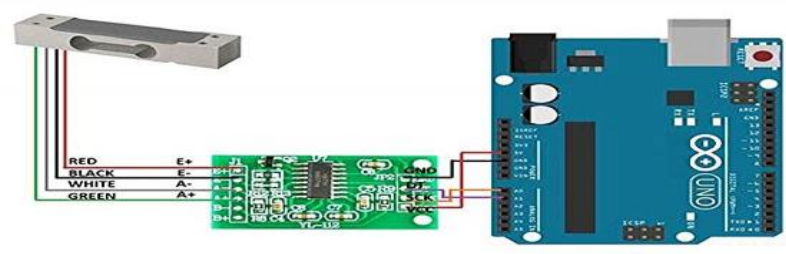

\section{ARDUINO:}

Arduino is a computer hardware and Software Company which designs and manufactures microcontroller kits. This for building Analog, digital devices and interactive objects that can sense and control objects in a physical world. Arduino allows programs, which will be written in any programming language with a compiler that can produce binary machine code. AVR microcontrollers, AVR Studio and the newer Atmel Studio can be used for programming Arduino. The integrated development environment (IDE) is a cross platform applications to be written in java provides by the Arduino Projects. A code or program created using IDE for Arduino is called as a "sketch". Arduino is in this project for controlling the interfacing devices like load cell, switches, LCD display. Load cell provides the input to arduino UNO and as the program stored in it arduino shows the count.

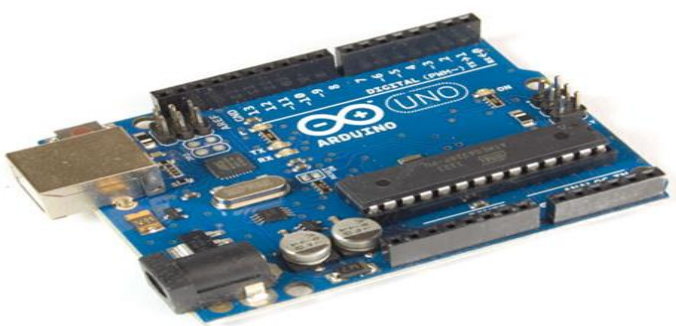

Fig: Arduino UNO

\section{6*2 LCD Display:}

Out of all available LCD Displays modules in market, the most commonly used one is $16 \times 2$ LCD Module which can display 32 ASCII characters in 2 lines (16 characters in 1 line and other 16 characters in 2 lines). The LCD module and Arduino are interfaced. To display the information on display like count, weight and project title.

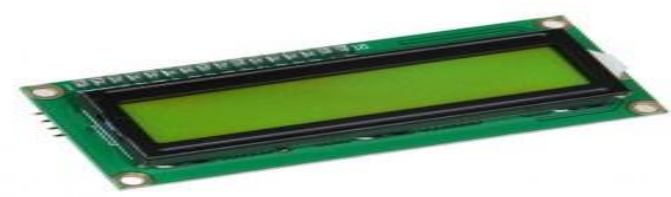

$16 \times 2$ LCD pinout diagram

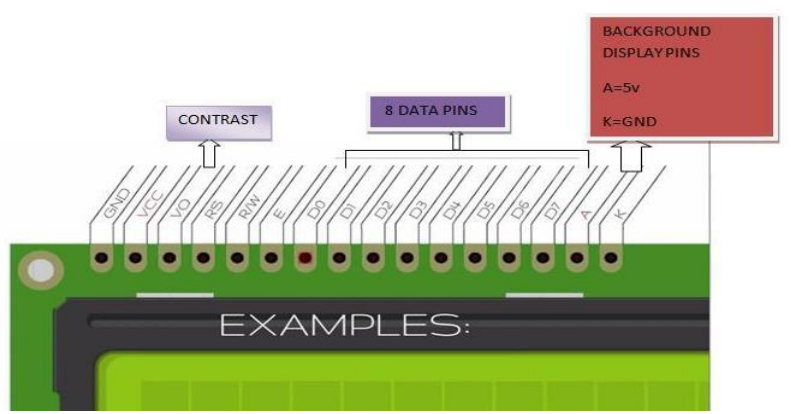


Push Switches:

There is three switches for selection of part size (small/medium/large). Three tactical switches are connected to the Arduino with three different pins.

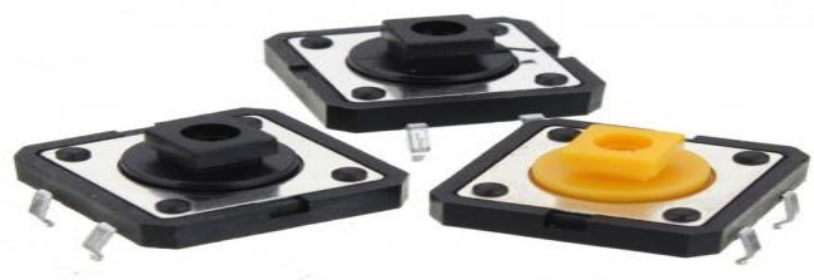

VIII.IMPLEMENTATION AND MACHANISM

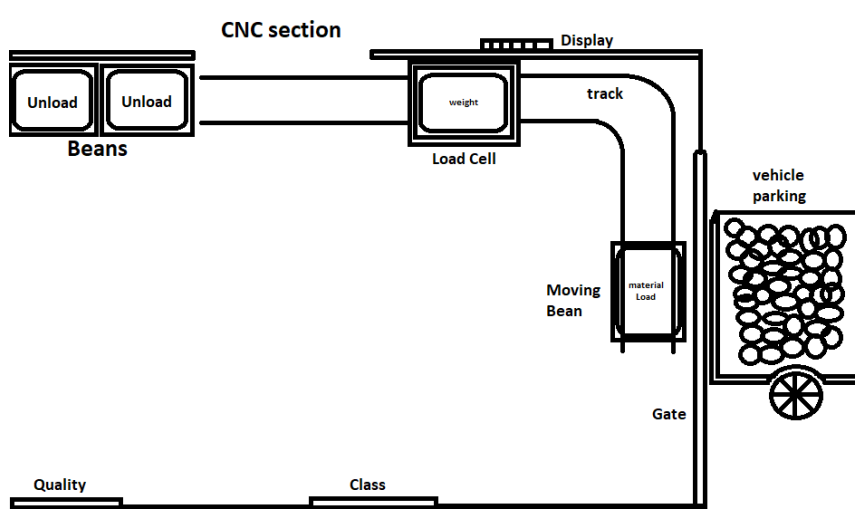

Fig. Implementation mechanism layout

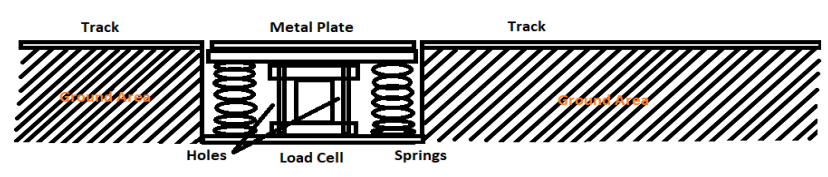

Fig. Internal Structure of Load Cell arrangment

Fig. Internal arrangement/mechanism of load cell

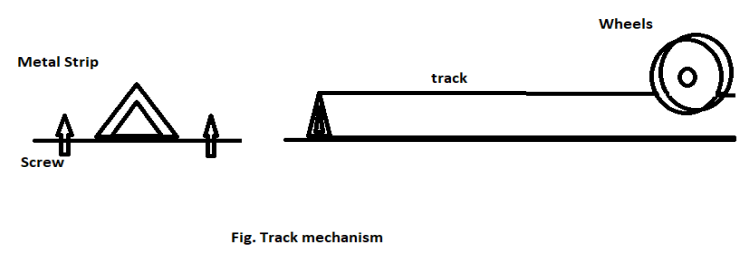

Fig. Track mechanism and mechanical arrangement

\section{CONCLUSION}

In now a day any work doing manually or use a man power is not suitable, because of very high level automation use in industries. We are not use man power for small work heavy works. As a result of this, required more time for work, need more man power and cost of this is very high. So as to eradicate these problems so we are introducing highly advanced system known as Raw Material Counting scale for small industries. It can be useful for many industries and it has large number of applications in industries and introducing a high scope in the future. The proposed system is more effective and accurate because it has measured weight as well as showing the count. So it is mainly designed for the consuming less time, less man power, work simple and less losses. Using Microcontroller, it indicates us count and calibration. In future this will also upgrades and we can send the notification of count to company owner and supplier.

\section{REFERENCES}

[1] Nikita Mahajan, Neha Bhosale, Mamta Khatape "Study of weight measurement system using PIC microcontroller," International Journal of Advanced Scientific and Technical Research. Issue 4 volume 4 July-August 2014 pp. 171-183

[2] Dr. Pradeep Dahikar, Mr. Kamlesh Patle "Design of an Embedded platform for Digital weighing system to enhance measuring capabilities," International Journal of Innovative Research in Computer and Communication engineering. In the Volume 1 Issue october 2013

[3] Kimani Peter Ng'ang'a "Microcontroller Based weighing Machine," final year project, Electrical and Electronic Engineering of the University of Nairobi. 22 may 2014

[4] Kitavi "Design and fabrication of microcontroller based electronic weighing machine in high mass regime," from Kenyatta University, in August 2009

[5] S.A Fagbemi, M. Momoh, I.G. Saidu, D. Akpootu, S.B. Sharafa and Abdulsalami "Digitalisation of an Analogue weighing scale using Microcontroller." IOSR- Journal of environmental science, Toxicology and Food Technology. In the Volume 8, Issue MarchApril 2014.

[6] Victor O. Matthews, Etinosa Noma-Osaghae, Uzairue Stanley Idiake "An Analytics Enabled wireless AntiIntruder Monitoring and Alarm System," International Journal of Scientific Research in Science, Engineering and Technology. Volume 4 issue 9, July-August 2018 pp.5-11

[7] Victor O. Matthews, Uzairue Stanley Idiake, Etinosa Noma-Osague, Morgan Kubiat Enefiok, Praise Jude Ogukah "International Journal of Innovative Science and Research Technology," volume 3 issue 6 june 2018

[8] Awodeyi Afolabi, Samuel Isaac Adekunle, Akindele Ayoola, Matthews Victor Olugbemiga, "Design and Construction of a Microcontroller Based Automated Intelligent Street Lighting System," International Journal of Scientific and Engineering Research. Volume 9 issue may 2018.

[9] Awodeyi Afolabi I., Makinde Opeyemi S., Ben-Obaje Abraham., Abayomi-Zannu Temmidayo P. "Design and Construction of Panic Button Alarm System for Security Emergencies," International Journal of Engineering and Techniques. In the Volume 4, Issue May-June 2018.

[10] Sandip N. Rikame, Pradip W. Kulkarmi. "Digital Electronics weighing machine operate on solar energy with emergency LED light," International Journal of Emerging Technology and Advanced Engineering. In the Volume 4 Issue July 2014

[11] Chukwuedozie N. Ezema, Albert C. Agulanma, Okechi Onuoha, Helen U. Nonyelu, Nwanyinnaya Nwogu "International Journal of Engineering Research and Reviews," in the Volume 4, Issue January-March2016. 